\title{
Effect of storage time on the hatchability of eggs of two-line dual-purpose combination for production of male chickens for meat
}

\author{
Evgeni Petkov*1, Teodora Popova ${ }^{1}$ \\ *corresponding author: mechovet@abv.bg \\ ${ }^{1}$ Institute of Animal Science- Kostinbrod, 2232 Kostinbrod, Bulgaria
}

\section{ABSTRACT}

The aim of the study was to assess the effect of the storage time on the hatching traits of eggs obtained from a two-line dual-purpose combination for production of male chickens that will be utilized for meat. The trial was carried out in the experimental poultry farm of the Institute of Animal Science-Kostinbrod, with a total of 150 Lohmann Brown Classic layers, at the age of 54 weeks. Hatching eggs were gathered for three weeks and were stored for 5,10 and 15 days at $15-18^{\circ} \mathrm{C}$ ambient temperature prior incubation. The storage time had no effect on the fertility of the set eggs, however, it adversely affected the hatchability. Prolonged storage led to significant decline in the total hatchability $(\mathrm{P}=0.0027)$ and the hatchability of the fertile eggs $(\mathrm{P}<0.0001)$ which was lowest after 15 days of storage prior incubation. The viability of the chickens was influenced by the storage of the eggs prior incubation $(\mathrm{P}<0.0001)$, and decreased considerably when the chicks were hatched from eggs stored for 15 days.

Keywords: dual-purpose combination, eggs, storage time, hatchability

\section{INTRODUCTION}

The development and use of the modern chicken genotypes with high egg or meat performance imposes an issue for the male layer type chickens. The latter have long fattening period, unfavourable feed efficiency and poor meatiness (Murawska et al., 2005; Mueller et al., 2018). Hence, they are usually killed immediately after hatching. This is a common practice, raising, however, ethical debates in public (Vizier Thaxton et al., 2016). In recent years, three different approaches to avoid of the killing of the male layer type chickens have been applied. These are in ovo sex determination, rearing of male layers for meat, and the use of dual-purpose breeds (Giersberg and 
Kemper, 2018). The two-line combination used in this study has been developed in the Institute of Animal Science -Kostinbrod from Lohmann Brown Classic layers and Bresse Gauloise cocks. Bresse Gauloise is principally known as meat breed, but it is also a good layer, which makes the combination mainly used for egg production. We consider this combination suitable for production of male chickens that should be further reared for meat production. As stated by Peters et al. (2008), fertility and hatchability of the eggs are the main determinants of the profitability of a hatchery. Egg storage prior to incubation might affect the hatchability, that usually declines with prolonged storage (Petek and Dikmen, 2006). However, storage time can significantly interact with other factors such as breeders age (Nasri et al., 2019), breeds of poultry, etc. Most of the studies evaluating the effect of these factors on hatching traits of eggs were done with commercial or local broilers (Petek and Dikmen, 2006; Goliomytis et al. 2015; Raharja et al., 2020, Melo et al., 2021), ducks (Onbasilar et al., 2007; Abd El-Hack et al., 2019), quails (Yildirim, 2005; Aygun and Sert, 2013), whereas research with dual-purpose lines remain scarce. This study thus evaluates the hatchability traits of eggs derived from a dual-purpose combination as affected by the storage period prior incubation.

\section{MATERIALS AND METHODS}

The experimental protocol used in this study, including the animal management and housing was approved by the ethical committee of the Institute of Animal Science-Kostinbrod, Bulgaria. It was designed in compliance with the guidelines of the European and Bulgarian legislation regarding the protection of animals used for experimental and other scientific purposes (Directive 2010/63; EC, 2010 - put into law in Bulgaria with Regulation 20/2012).

\section{Experimental birds and housing}

The trial was carried out in the experimental poultry farm of the Institute of Animal Science- Kostinbrod with a total of 150 Lohmann Brown Classic layers at 54 weeks of age. The hens were housed in 15 pens $(4.5 \mathrm{~m} \times 3.8 \mathrm{~m})$ at 10 hens per pen, forming 15 replicates. Fifteen Bresse Gauloise cocks were mixed with the hens ( 1 cock per replicate). The birds were fed according to the standards for Lohmann hens (+48 weeks of age). The diet composition is presented in Table 1. The cocks were fed the same diet as the layers but in separate feeders. The drinkers were common for both layers and cocks. 
Table 1. Diet composition

Component

$\%$

Maize

Soybean meal

Sunflower meal

57.521

Sunflower oil

Limestone

Monocalcium phosphate

Salt

L-Lys

DL- Met

Vitamin premix*

Mineral premix ${ }^{* *}$

Chemical composition

Crude Protein, \%

Fat, \%

Ash, \%

Crude Fibers, \%

$\mathbf{P}$

Metabolizable energy, $\mathrm{kcal} / \mathrm{kg}^{* * *}$
18.04

50.43

3.55

0.54

16.50

13.4

1.9

9.55

0.515

0.52

0.004

0.05

0.02

0.02

2701.38

Note: *Vitamin and **mineral premix provided the following per kg of diet: $\mathrm{Fe}, 140 \mathrm{mg}$; $\mathrm{Cu}$, 18 mg; Zn, 110 mg; Mn, 120 mg; I, 1.8 mg; Se, 0.35 mg; vit. A, 9900 IU; vit. D, 3000 IU; vit. E, $30 \mathrm{mg}$; BHT, 0.1; BHA, $0.1 \mathrm{mg}, 1,4$ beta-xylanase, $1500 \mathrm{EPU}$, ***Metabolizable energy was calculated using the Komfu software system for composing an optimisation of animal feeds (provided by Exbit Ltd.)

\section{Hatching traits and incubation}

The hatching traits were measured in a total of 1388 eggs. They were collected for three weeks and were stored for 5,10 and 15 days at $15-18^{\circ} \mathrm{C}$ ambient temperature. The eggs were then incubated at $37.4^{\circ} \mathrm{C}$ until 18-th day and then $37.2^{\circ} \mathrm{C}$, the humidity in the incubator was kept at $57 \%$ for 18 days, then on day 19 it was augmented to $60 \%$, on day 20 it was $65 \%$, and on day 21 it was $75 \%$. The hatching traits were determined at the end of the experimental period for each of the three groups of eggs according to their storage. The parameters controlled included the number of the fertile and hatched eggs and viable chickens (Table 2). They were used to calculate the 
fertility, the hatchability of the fertile eggs, hatchability of the set eggs, and the viable chickens as percentage of all the hatched eggs.

Table 2. Number of the fertile eggs, hatched eggs and viable chickens

\begin{tabular}{ccccc}
\hline $\begin{array}{c}\text { Storage } \\
\text { period, } \mathbf{d}\end{array}$ & $\begin{array}{c}\text { Eggs set for } \\
\text { incubation }\end{array}$ & Fertile eggs & Hatched eggs & $\begin{array}{c}\text { Viable } \\
\text { chickens }\end{array}$ \\
\hline 5 & 475 & 403 & 327 & 324 \\
10 & 477 & 402 & 305 & 291 \\
15 & 436 & 369 & 234 & 186 \\
\hline
\end{tabular}

\section{Statistical evaluation}

The data were statistically evaluated using JMP, v.7 software package. The effect of the storage time of the eggs on their hatching traits was assessed through one way ANOVA. In case of significant effect, the difference between groups were determined through post hoc comparison by Tukey HSD test at $\mathrm{P}<0.05$.

\section{RESULTS AND DISCUSSION}

The average fertility of the eggs in this study was $84.8 \%$. This is higher than the reported by Khan et al. (2014) (78.26\%) in Rhode Island Red but similar to that recorded by Islam et al. (2013) in the same breed. The latter however reported higher than our fertility for White Leghorn and White Rock. The storage time of the eggs prior incubation did not affect the fertility of the set eggs (Fig. 1). It was similar in the three groups of eggs $(84.82 \%, 84.49 \%$ and $84.96 \%$, respectively for the eggs stored 5, 10 and 15 days).

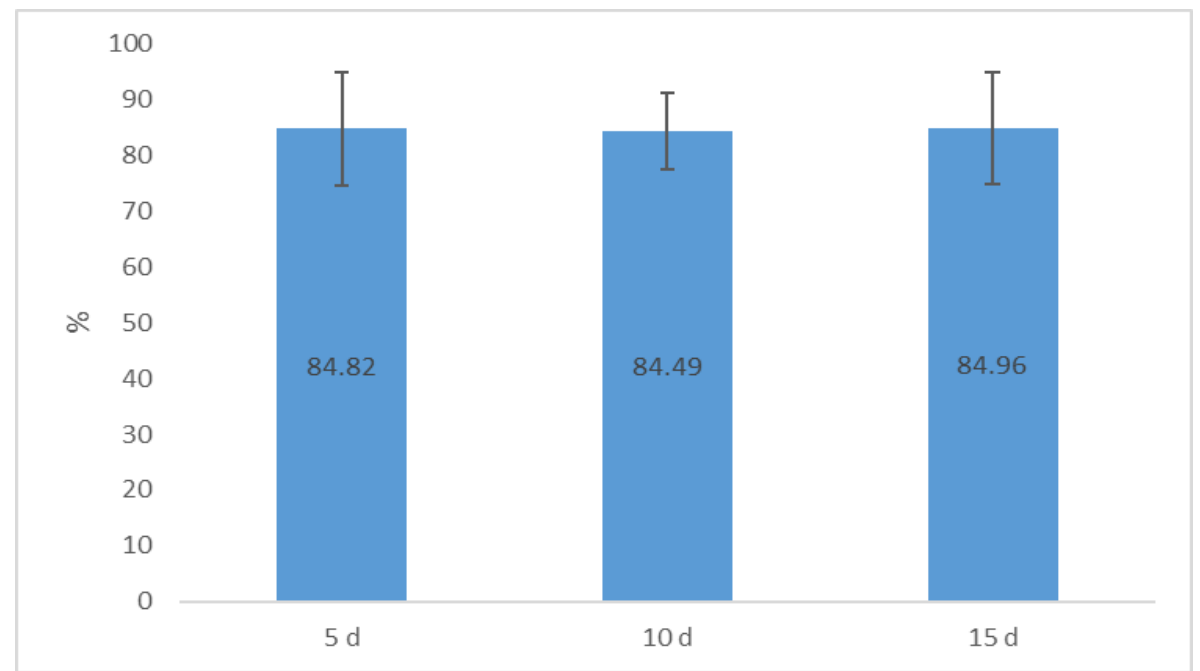

Figure 1. Fertility of the eggs according to the time of storage, $\%$ 
In line with our results, Khan et al. (2013) did not find any effect of the storage period on the fertility of Fayoumi eggs. However, Addo et al. (2018) found considerable decrease in fertility during storage of eggs from Naked Neck chickens, mostly pronounced between 7 and 14 days, when the fertility fell from $86.67 \%$ to $40 \%$. The authors also found effect of the storage temperature on the fertility, showing significantly higher fertility in eggs stored at $18^{\circ} \mathrm{C}$ than in the ambient temperature of $23-31^{\circ} \mathrm{C}$.

The storage time affected significantly the hatchability of the eggs. The hatchability of the set eggs declined with storage ( $\mathrm{P}=0.0027)$ (Fig.2).

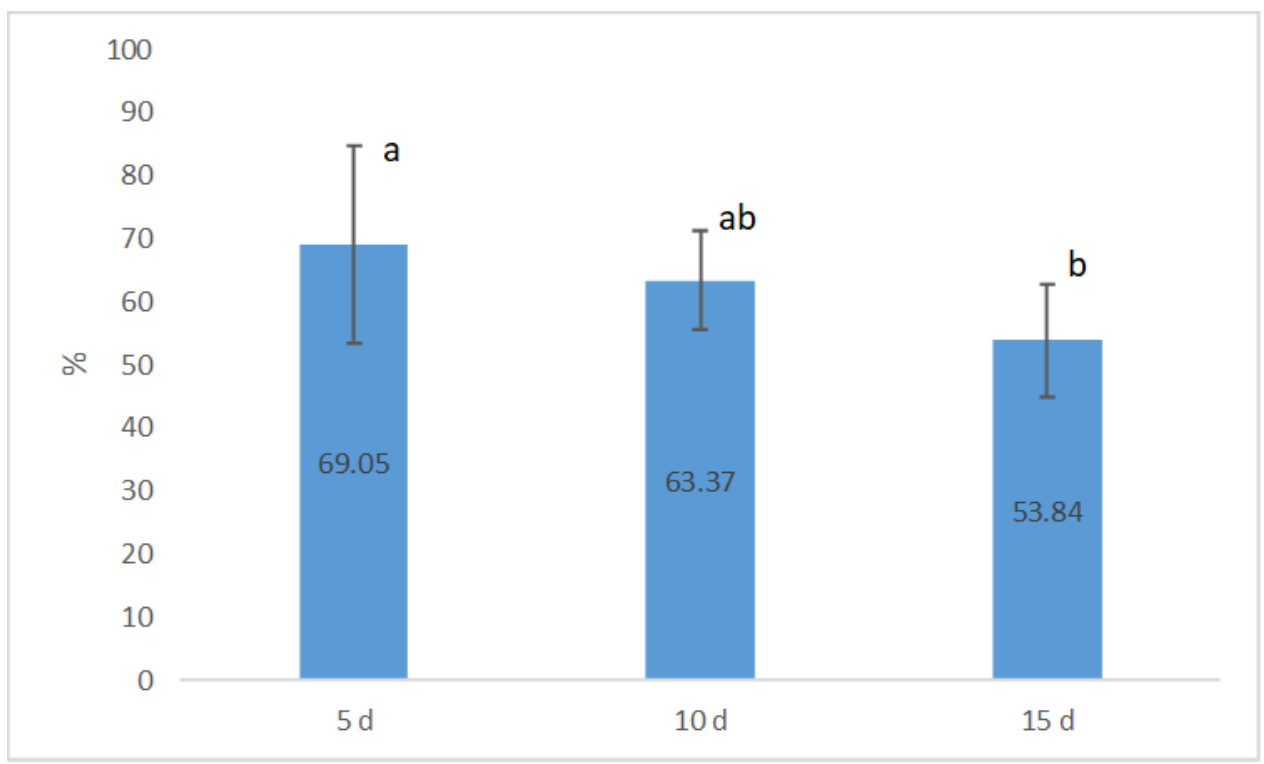

Figure 2. Hatchability of the set eggs, \%

After 15 days it was $53.84 \%$, in comparison to $69.05 \%$ after 5 th day and $63.37 \%$ after 10 th day. Similarly, the hatchability of the fertile eggs declined $(\mathrm{P}<0.0001)$ showing lowest values after 15 days of storage $(63 \%$ vs. $81.38 \%$ and $75.05 \%$, respectively for the $5^{\text {th }}$ and $10^{\text {th }}$ day of storage) (Fig.3). The percentage of the viable chicks was high when hatched from eggs stored 5 days $(99.03 \%)$ and 10 days $(94.85 \%)$, however the percent decreased considerably after 15 days of storage $(78.12 \%, \mathrm{P}<0.0001)$ (Fig.4). 


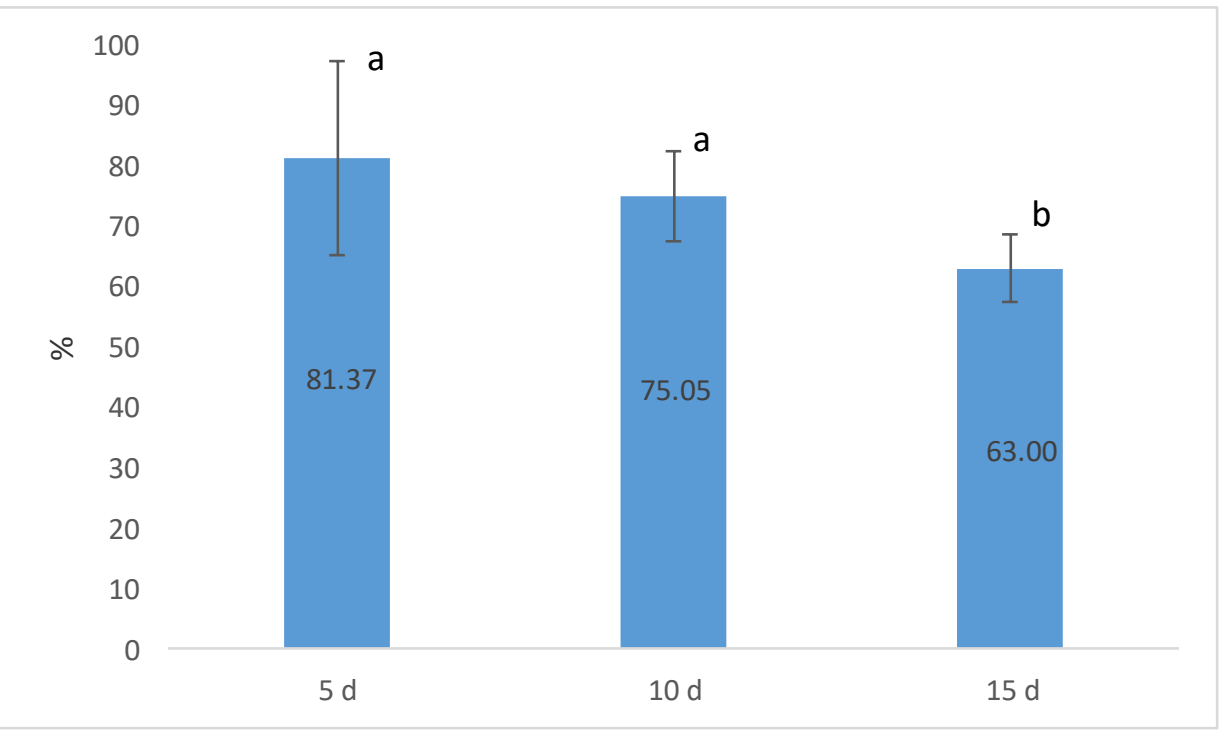

Figure 3. Hatchability of the fertile eggs, $\%$

The results of this study show that the hatching traits were negatively affected by the prolonged storage of the eggs prior incubation.

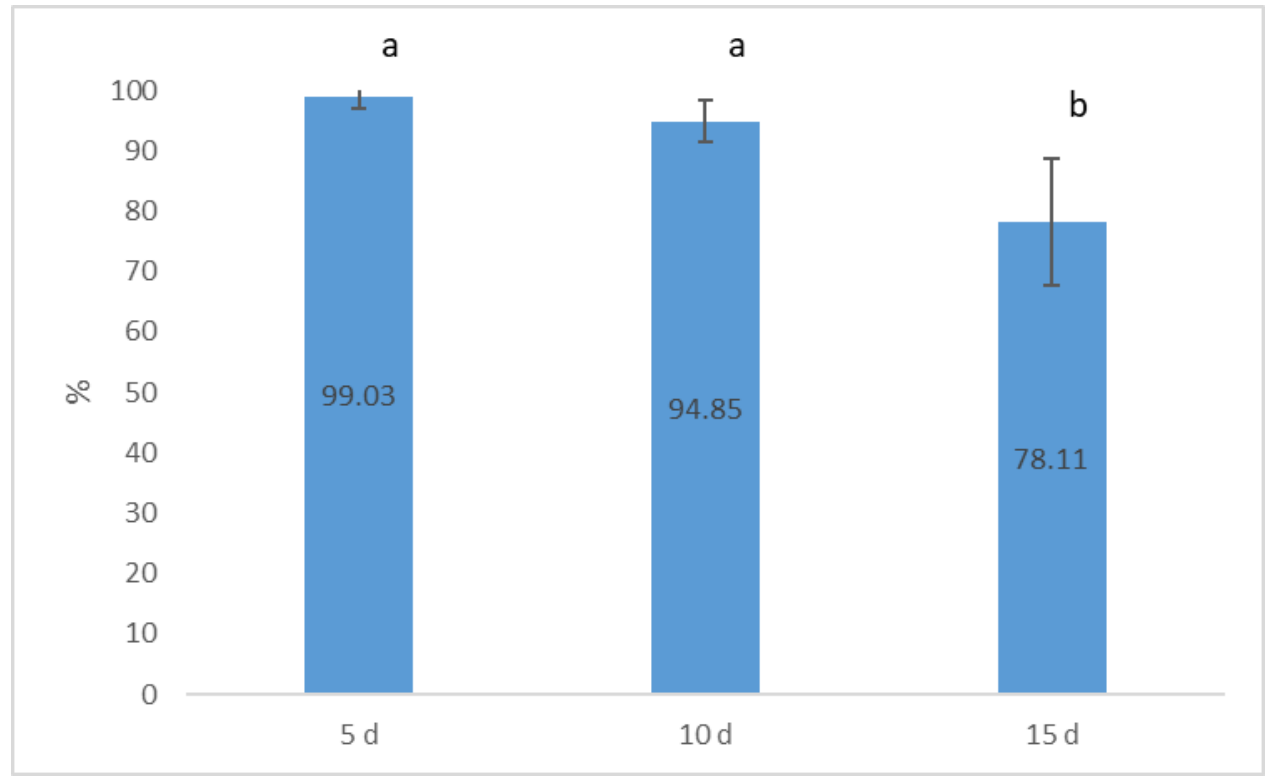

Figure 4. Viable chickens, hatched from the set eggs, $\%$ 
It has been well documented in previous studies that the hatchability declines considerably in eggs stored longer than 7 days for various domestic avian species (Fasenko et al., 1999; Fasenko et al., 2001a, b). In a review on the egg storage, Fasenko (2007) stated that at cellular level, longer egg storage induces death of the cells. This is associated with higher embryo mortality and hence lower hatchability. Similarly, Saffaa et al. (2013) found that the hatchability significantly declined in eggs of local Egyptian and commercial broiler breeders stored for 7 and 10 days compared to 3 days. The authors also found that the embryonic mortality during the first three days of incubation tended to be higher in response to the increased storage time of the eggs. Similar results were shared by Molapo et al. (2021), who showed significant decline in the hatching percentage in eggs stored for 7 and 11 days in comparison to those stored for 3 days. These authors also reported increased mid and late embryonic mortality in the eggs stored longer as well as higher chickens' mortality after hatching from eggs stored for 7 and 11 days. This is in line with our results, revealing lowest percentage of the viable chicks hatched from the eggs stored for 15 days, as well as the lowest hatchability of the eggs after storing for the same period. According to Ayeni et al. (2020), the storage time of the eggs should not exceed 4 days for optimum hatchability and weight of the hatched eggs.

\section{CONCLUSION}

The study revealed that the storage of the eggs prior incubation did not influence the fertility of the eggs but had the detrimental effect on their hatchability and viability of chickens. The hatchability and the percentage of viable chickens declined considerably between 10th and 15th day of egg storage, when they reached minimal values. The results proved that in order to keep good hatchability the eggs should not be stored for more than 10 days prior incubation.

\section{REFERENCES}

Abd El-Hack, M., Hurtado, C., Toro, D., Alagawany, M., Abdelfattah, E., Elnesr, S., 2019. Fertility and hatchability in duck eggs. World Poult Sci J, 75, 599608.

Addo, A., Hamidu, J.A., Ansah, A.Y., Adomako, K., 2018. Impact of egg storage duration and temperature on egg quality, fertility, hatchability and chick quality in Naked Neck chickens. Int J PoultSci, 17, 175-183.

Ayeni, A.O., Agbede, J.O., Igbasan, F.A., Onibi, G.E., Adegbenro, M., 2020. Effects of storage periods and positioning during storage on hatchability and 
weight of the hatched chicks from different egg sizes. Bull Natl Res Cent, 44, 101.

Aygun, A., Sert, D., 2013. Effects of prestorage application of propolis and storage time on eggshell microbial activity, hatchability, and chick performance in Japanese quail (Coturnix coturnix japonica) eggs. Poult Sci, 92, 3330-3337.

Fasenko, G. M., Christensen, V. L., Wineland, M. J., Petitte, J. N., 2001a. Examining the effects of prestorage incubation of turkey breeder eggs on embryonic development and hatchability of eggs stored for four or fourteen days. Poult Sci, 80, 132-138.

Fasenko, G. M., Robinson, F. E., 1999. Profiling egg storage: The effects on egg weight loss, egg characteristics, and hatchability. Poult Sci, 78 (Suppl. 1), 9. (Abstr.)

Fasenko, G. M., Robinson, F. E., Whelan, A. I., Kremeniuk, K. M., Walker, J. A., 2001b. Prestorage incubation of long-term stored broiler breeder eggs. 1. Effects on hatchability. Poult Sci, 80, 1406-1411.

Fasenko, G.M., 2007. Egg storage and the embryo. Poult Sci, 86, 1020-1024.

Giersberg, M. F., Kemper, N., 2018. Rearing Male Layer Chickens: A German Perspective, Agriculture, 8, 176.

Goliomytis, M., Tsipouzian, T., Hager-Theodorides, A. L., 2015. Effects of egg storage on hatchability, chick quality, performance and immunocompetence parameters of broiler chickens. Poult Sci, 94(9), 2257-2265.

Islam, M. S., Howlider, M. A. R., Kabir, F., Alam, J., 2002. Comparative assessment of fertility and hatchability of Barred Plymouth Rock, White Leghorn, Rhode Island Red and White Rock hen. Int J Poult Sci, 1, 85-90.

Khan, M. J. A., Khan, S.H., Bukhsh, A., Abbass, M. I., Javed, M., 2013. Effect of different storage period on egg weight, internal egg quality and hatchability characteristics of Fayumi eggs. It J Anim Sci, 12, e51.

Khan, M. J. A., Khan, S.H., Bukhsh, A., Amin, M., 2014. The effect of storage time on egg quality and hatchability characteristics of Rhode Island Red (RIR) hens Vet Vet Arhiv 84, 291-303.

Melo, E.F., Araújo, I.C.S., Triginelli, M.V., Castro, F.L.S., Baião, N.C., Lara, L.J.C., 2021. Effect of egg storage duration and egg turning during storage on egg quality and hatching of broiler hatching eggs. Animal, 15, 100111.

Molapo, S.M., Mahlehla, M., Kompi, P.P., Taoana, M., 2021. Effect of egg storage length on hatchability and survival of Koekoek chickens. J World Poult Res, 11, 31-35.

Mueller, S., Kreuzer, M., Siegrist, M., Mannale, K., Messikommer, R.E., Gangnat, I.D.M., 2018. Carcass and meat quality of dual-purpose chickens (Lohmann Dual, Belgian Malines, Schweizerhuhn) in comparison to broiler and layer chicken types. Poult Sci, 97, 3325-3336. 
Murawska, D., Bochno, R., Michalik, D., Janiszewska, M., 2005. Age-related changes in the carcass tissue composition and distribution of meat and fat with skin in carcasses of laying-type cockerels. Europ Poult Sci, 69,135-139.

Nasri, H., van den Brand, H., Najjar, T., Bouzouaia, M., 2019. Egg storage and breeder age impact on egg quality and embryo development. J Anim Physiol Anim Nutr, 104, 257-268.

Onbaşılar, E.E., Poyraz, Ö., Erdem, E., 2007. Effects of egg storage period on hatching egg quality, hatchability, chick quality and relative growth in Pekin ducks, Arch Geflügelk, 71, S. 187- 191.

Petek, M., Dikmen, S., 2006. The effects of prestorage incubation and length of storage of broiler breeder eggs on hatchability and subsequent growth performance of progeny. Czech J Anim Sci, 51, 73-77.

Peters, S.O., Shoyebo, O.O., Ilori, B.M., Ozoje, M.O., Ikeobi, C.O.N., Adebambo, O.A., 2008. Semen quality traits of seven strains of chickens raised in the humid tropics. Int J Poult Sci, 7, 949-953.

Rahardja, D.P., Hakim, M. R., Empra, T., Sahrul, Savitri, R.D., 2020. Effects of weight and storage duration of hatching eggs of Indonesian Local Chicken on several measures of internal quality and hatchability. The 2nd International Conference of Animal Science and Technology IOP Conf. Series: Earth and Environmental Science 492 (2020) 012034. doi:10.1088/1755-1315/492/1/012034

Safaa, H.M., Sobhy, H.N., Elsemary, M.S.A., 2013. Influence of egg storage time on egg quality, hatchability and chick quality traits of commercial and Egyptian Local Broiler breeders. Aust J Basic Appl Sci, 7(13), 154-163.

Vizzier Thaxton, Y., Christensen, K.D., Mench, J.A., Rumley, E.R., Daugherty, C., Feinberg, B., Parker, M., Siegel, P., Scanes, C.G., 2016. Symposium: Animal welfare challenges for today and tomorrow, Poult Sci, 95, 2198-2207. 